\title{
Evaluation of Antioxidant Activities of Ethanol Extracted Garlic and Onion as Affected by Pre-heating for the Application of Meat Products
}

\author{
Sung Yong Park and Koo Bok Chin* \\ Department of Animal Science and Biotechnology Research Institute, Chonnam National University, \\ Gwangju 500-757, Korea
}

\begin{abstract}
The objective of this study was to evaluate the pre-heating treatment effects on the antioxidant properties of ethanolic garlic and onion extracts. Garlic and onion with or without heating $\left(100^{\circ} \mathrm{C}, 30 \mathrm{~min}\right)$ were extracted with ethanol, and the total phenolic content, 1,1-diphenyl-2-picrylhydrazyl (DPPH) radical scavenging ability, iron chelating ability, reducing power, and antioxidant activity in a linoleic acid emulsion system were evaluated. Garlic (41\%) had a higher drying yield than onion (11\%). Regardless of pre-heating, ethanol extracts of onion resulted in an approximately 25 -fold higher yield than those of garlic. Thermal treatment before extraction decreased the levels of ethanol-soluble phenolics for both garlic and onion. Regardless of pre-heating, the radical scavenging abilities of ethanol extracts from garlic were greater than the ethanol extracts from onion. The iron chelating abilities of ethanol extracts from fresh and heated garlic were 85 and $81 \%$ at 10 $\mathrm{mg} / \mathrm{mL}$, respectively, whereas those of onion extracts were 10 and $9 \%$ at the same concentration, respectively. However, no differences in reducing power between garlic and onion extracts were observed. Both garlic and onion inhibited the formation of hydroperoxide in linoleic acid emulsion systems when ethanol was used as a solvent. Overall, garlic extracts had greater antioxidant activity than onion extracts, and the antioxidant activity of garlic and onion extracts were not significantly affected by thermal treatment.
\end{abstract}

Key words: garlic, onion, antioxidant activity, pre-heating

\section{Introduction}

Animal fats in muscle foods are considered to be important factors affecting food quality. These fats provide nutritional values, essential fatty acids and desirable sensory characteristics. However, lipid oxidation deteriorates nutritional values and shortens shelf-life of meat and meat products, and produces undesirable flavor and color, which decreases consumer's acceptance. Therefore, lipid oxidation is a major cause of quality deterioration in flavor, color, texture, nutritional values and safety of meat and meat products. To reduce lipid oxidation, many studies related to natural or synthetic antioxidants have been widely performed (Ahn et al., 2007; Bozkurt, 2006a). However, synthetic antioxidants such as butylated hydroxyl toluene (BHT), butylated hydroxyl anisole (BHA) and tert-butyl hydroquinone (TBHQ) are limited to use as additive

\footnotetext{
*Corresponding author: Koo B. Chin, Department of Animal Science and Biotechnology, Research Institute, Chonnam National University, Gwangju 500-757, Korea, Tel: 82-62-5302121, Fax: 82-62-530-2129, E-mail: kbchin@chonnam.ac.kr
}

agents in food systems because they contain many factors hazardous to health (Branen, 1975). Hence, antioxidants derived from natural resources are perceived by consumers as being better and safer than synthetics. Among natural sources, garlic (Allium sativum) and onion (Allium сера) have been used as a spice food and medicine for over 4,000 years (Ali et al., 2000). Both garlic and onion are known to possess various biological functions, including antioxidant and antimicrobial activities (Corzo-Martinez et al., 2007; Lanzotti, 2006). These biological functions may be due to the presence of organo-sulfur and phenolic compounds (Miean and Mohamed, 2001). However, processing of garlic and onion, especially heat treatment, may change their components, and consequently either increase or decrease the functionality of garlic and onion. Therefore, the objective of this study were to evaluate the antioxidant properties of ethanolic garlic and onion extracts as affected by pre-heating. 


\section{Materials and Methods}

\section{Preparation of garlic and onion extracts}

The garlic (Allium sativum) and onion (Allium cepa) were purchased from a local market. The extracts from the garlic bulbs and onion were obtained as follows: The garlic and onion were peeled and washed with double deionized (dd) water. One batch of garlic or onion was heated at $100^{\circ} \mathrm{C}$ for $30 \mathrm{~min}$ to determine the effect of heating. Two batches (fresh and heated) of garlic or onion were freeze-dried. The freeze-dried samples were crushed and homogenized with 10 volumes of ethanol $(94.0 \%)$ at $10,000 \mathrm{rpm}$ for $5 \mathrm{~min}$ using a homogenizer (AM-3, Ace Homogenizer, Nissei, Tokyo, Japan), and then extracted by stirring at room temperature for $24 \mathrm{~h}$. The ethanol extracts were filtered using filter paper (Whatman No. 1). The filtrates were rotary-evaporated at $40^{\circ} \mathrm{C}$ to evaporate the ethanol (Rotavapor, R110, Buchi, Flawil, Switzerland), and then the extracts were freeze-dried to remove the residual moisture.

\section{Determination of total phenolic content}

The total phenolic contents of the garlic and onion extracts were determined using the method described by Lin and Tang (2007). Briefly, $0.1 \mathrm{~g}$ of extract was dissolved in dd-water $(10 \mathrm{~mL})$. Then, $0.1 \mathrm{~mL}$ of this mixture was added to dd-water $(2.8 \mathrm{~mL}), 2 \%$ sodium carbonate $(2 \mathrm{~mL}$, $\left.\mathrm{Na}_{2} \mathrm{CO}_{3}\right)$ and $50 \%$ Folin-Ciocalteau reagent $(0.1 \mathrm{~mL})$, and vortexed. After the reaction mixture was then incubated at room temperature for $30 \mathrm{~min}$, the absorbance of mixture was measured at $750 \mathrm{~nm}$ against a blank on a spectrophotometer (UV-1601, UV-Visible Spectrophotometer, Shimadzu, Australia). Gallic acid was used as a standard $(0-200 \mathrm{ug} / \mathrm{mL})$. All data were expressed as g gallic acid equivalents (GAE)/100 $\mathrm{g}$ of dried extracts.

\section{1,1-Diphenyl-2-picrylhydrazyl (DPPH) radical scavenging activity}

The radical scavenging activities of garlic and onion extracts were measured based on their ability to scavenge DPPH-radicals, which was determined according to the method described by Huang et al. (2006). Approximately $4 \mathrm{~mL}$ of each extract $(1-20 \mathrm{mg} / \mathrm{mL}$ in dd-water) was mixed with $1 \mathrm{~mL}$ of $0.2 \mathrm{mM}$ methanolic DPPH-radical solution. The mixture was then vortexed, and it was incubated at room temperature for $30 \mathrm{~min}$ in dark room. Then, the absorbance was measured at $517 \mathrm{~nm}$ against a blank (UV-1601, UV-Visible Spectrophotometer, Shimadzu, Australia). Ascorbic acid was used for com- parison with garlic and onion extracts. The scavenging activity was calculated as follows:

$$
\begin{aligned}
& \text { Scavenging activity }(\%)= \\
& \frac{\Delta A_{517} \text { of control }-\Delta A_{517} \text { of sample }}{\Delta A_{517} \text { of control }} \times 100
\end{aligned}
$$

\section{Ferrous iron chelating ability}

The ferrous ion chelating abilities of the garlic and onion extracts were determined by measuring the inhibition of the formation of a $\mathrm{Fe}^{2+}$-ferrozine complex using the method described by Le et al. (2007). The extracts $(0.5 \mathrm{~mL}$ of $1-20 \mathrm{mg} / \mathrm{mL}$ in dd-water), ferrous chloride $(0.1 \mathrm{~mL}, 0.6 \mathrm{mM}$ in dd-water) and methanol $(0.9 \mathrm{~mL})$ were combined, shaken well and then allowed to react at room temperature for $5 \mathrm{~min}$. After the reaction, ferrozine $(0.1 \mathrm{~mL}, 5 \mathrm{mM}$ in methanol) was added and the sample was then allowed to react at room temperature for $10 \mathrm{~min}$. The absorbance of the $\mathrm{Fe}^{2+}$-ferrozine complex was then measured at $562 \mathrm{~nm}$ against a blank (UV-1601, UV-Visible Spectrophotometer, Shimadzu, Australia). 2Na.EDTA $\cdot 2 \mathrm{H}_{2} \mathrm{O}$ (Ethylene diaminetetraacetic acid disodium salt dihydrate) was used for comparison with garlic and onion extracts. The chelating effect was then calculated as a percentage using the following equation:

$$
\begin{aligned}
& \text { Chelating effect }(\%)= \\
& \frac{\Delta A_{562} \text { of control }-\Delta A_{562} \text { of sample }}{\Delta A_{562} \text { of control }} \times 100
\end{aligned}
$$

\section{Reducing power}

The reducing power was measured using the method described by Huang et al. (2006). Briefly, each extract (2.5 mL of $1-20 \mathrm{mg} / \mathrm{mL}$ in dd-water) was mixed with sodium phosphate buffer $(2.5 \mathrm{~mL}, 200 \mathrm{mM}, \mathrm{pH}$ 6.6) and potassium ferricyanide $(2.5 \mathrm{~mL}, 10 \mathrm{mg} / \mathrm{mL})$, after which the mixture was incubated at $50^{\circ} \mathrm{C}$ for $20 \mathrm{~min}$. Then, trichloroacetic acid $(2.5 \mathrm{~mL}, 100 \mathrm{mg} / \mathrm{mL})$ was added and the mixture was centrifuged at $200 \times g$ for $10 \mathrm{~min}$. After the upper layer $(5 \mathrm{~mL})$ was then mixed with dd-water $(5 \mathrm{~mL})$ and ferric chloride $(1 \mathrm{~mL}, 1 \mathrm{mg} / \mathrm{mL})$, the absorbance at $700 \mathrm{~nm}$ was measured against a blank in a spectrophotometer (UV-1601, UV-Visible Spectrophotometer, Shimadzu, Australia). The higher absorbance indicates the higher reducing power.

\section{Antioxidant activity in linoleic acid emulsion}

The antioxidant activity of garlic and onion extracts in linoleic acid emulsion system was determined using the thiocyanate method described by Yen and Hsieh (1998). 
Briefly, extracts (500 ug in $0.5 \mathrm{~mL}$ of dd-water) of garlic or onion were mixed with phosphate buffer $(2 \mathrm{~mL}, 0.2 \mathrm{M}$, $\mathrm{pH} 7.0)$ and linoleic acid emulsion $(2.5 \mathrm{~mL}, 0.02 \mathrm{M}, \mathrm{pH}$ 7.0). The absorbance of mixture was measured during incubation at $37^{\circ} \mathrm{C}$. Ethanol $(4.7 \mathrm{~mL}, 75 \%)$, ammonium thiocyanate $(0.1 \mathrm{~mL}, 30 \%)$, sample mixture $(0.1 \mathrm{~mL})$ and ferrous chloride $(0.1 \mathrm{~mL}, 0.02 \mathrm{M}$ in $3.5 \% \mathrm{HCl})$ were combined, vortexed and then allowed to react at room temperature for $3 \mathrm{~min}$. Then, the absorbance was measured at $500 \mathrm{~nm}$ against a blank in a spectrophotometer (UV-1601, UV-Visible Spectrophotometer, Shimadzu, Australia). The higher absorbance indicates the lower antioxidant activity.

\section{Statistical analysis}

Data were analyzed using one-way analysis of variance (ANOVA) with SPSS 14.0. Means were separated using Duncan's multiple range test. EC50 values were obtained by interpolation from linear regression analysis.

\section{Results and Discussion}

\section{Extraction yield and total phenolic content}

As shown in Table 1, the weights of garlic and onion decreased approximately 59 and 89\% after freeze-drying, respectively, regardless of heating. Therefore, the garlic had a higher drying yield than onion $(p<0.05)$. These results are similar to those of previous study (Abhayawick et al., 2002; Bae and Chun, 2003; Dini et al., 2008; Gorinstein et al., 2005; Shin et al., 1999). However, onion showed an approximately 25 -fold higher extraction yield than garlic $(p<0.05)$, regardless of thermal treatment. The levels of total phenolics ranged from 1.11 to $2.49 \%$ (Table 1 ), and ethanolic extracts from garlic contained more phenolic compounds than those from onion $(p<0.05)$. However, thermal treatment $\left(100^{\circ} \mathrm{C}, 30 \mathrm{~min}\right)$ significantly decreased phenolic compounds in both garlic and onion. Several previous studies have found that boiling garlic and onion decreased the level of total phenolics (Gorinstein et al., 2006; Gorinstein et al., 2008). Specifically,
Roy et al. (2007) and Makris and Rossiter (2001) found that the amount of total phenolics extracted from heated $\left(100^{\circ} \mathrm{C}, 60 \mathrm{~min}\right)$ garlic samples was approximately $35 \%$ lower than that of raw garlic, and that boiling $\left(100^{\circ} \mathrm{C}, 60\right.$ min) onion resulted in $20.6 \%$ decreases in total quercetins. The results of several studies have suggested that a decrease in total phenolic content by thermal treatment may be partially due to the degradation of a portion of the phenolic compounds by thermal processing (Randhir et al., 2008) or the breakdown of phenolics (Crozier et al., 1997). In actual meat products, types and amounts of phenolic compounds are very important in inhibition of lipid peroxidation because their radical scavenging ability, iron chelating ability and reducing power depend on position and amount of hydroxyl group in phenolic compounds (Kristinova et al., 2009; Medina et al., 2007). Onion contains many flavonols $(2720 \mathrm{mg} / \mathrm{kg})$. Especially, quercetin $(1497 \mathrm{mg} / \mathrm{kg}$ ) belonging to flavonols is the most typical phenolic compounds in onion (Lanzotti, 2006). According to results of Tang and Cronin (2007) who researched effects of onion on lipid oxidation of ground turkey, quercetin in onion was the main antioxidant. Antioxidant effect of quercetin was also found in ground beef patties; 110 and 550 quercetin umol $/ \mathrm{kg}$ of meat reduced 42.4 and $62.7 \%$ of TBARS value during storage at $2^{\circ} \mathrm{C}$ for $6 \mathrm{~d}$, respectively (Bekhit et al., 2003). Garlic not only possesses phenolic compounds such as myricetin and apigenin, but also contains many organosulfur compounds that have various functions (Corzo-Martinez et al., 2007; Lanzotti, 2006). Yin and Cheng (2003) studied antioxidant activities of four garlic-derived organo-sulfur compounds in ground beef found that both lipophilic-(diallyl sulfide and diallyl disulfide) and hydrophilic-( $s$-ethyl cysteine and $n$-acetyl cysteine) compounds dose-dependently delayed lipid oxidation, and showed significantly greater antioxidant activity than $\alpha$-tocopherol.

\section{1,1-Diphenyl-2-picrylhydrazyl (DPPH) radical scavenging activity}

Free radicals act as initiator in the process of lipid

Table 1. Dry and extraction yields, and total phenolic contents of ethanolic garlic and onion extracts as affected by pre-heating treatment

\begin{tabular}{lrrrrr}
\hline \hline & \multicolumn{2}{c}{ Garlic } & & \multicolumn{2}{c}{ Onion } \\
\cline { 2 - 3 } \cline { 5 - 6 } & Unheated & Heated & & Unheated & Heated \\
\hline Dry yield (g/100 g of fresh weight) & $41.35^{\mathrm{a}}$ & $41.52^{\mathrm{a}}$ & & $10.52^{\mathrm{b}}$ & $10.49^{\mathrm{b}}$ \\
Extraction yield (g/100 g of dry weight) & $2.46^{\mathrm{c}}$ & $2.15^{\mathrm{c}}$ & & $52.38^{\mathrm{b}}$ & $55.18^{\mathrm{a}}$ \\
Total phenolic (g GAE/100 g of extracts) & $2.49^{\mathrm{a}}$ & $1.56^{\mathrm{b}}$ & & $1.31^{\mathrm{c}}$ & $1.11^{\mathrm{d}}$ \\
\hline
\end{tabular}

\footnotetext{
${ }^{\mathrm{a}-\mathrm{d}}$ Means with same superscripts within same row are not different $(p>0.05)$.
} 
autoxidation, and the DPPH radical has been widely used to evaluate the antioxidant activity of various natural plants. Radical scavenging abilities of the four extracts increased as the concentration increased. As a reference, ascorbic acid showed an excellent scavenging ability of greater than $95.0 \%$ at a concentration of $0.05 \mathrm{mg} / \mathrm{mL}$. The scavenging abilities of ethanol extracts from fresh and heated garlic were 73.33 and $73.29 \%$ at $5 \mathrm{mg} / \mathrm{mL}$, respectively (Fig. 1). Ethanol extracts from onion showed lower radical scavenging ability than those from garlic, regardless of pre-heating. These results were supported by the $\mathrm{EC}_{50}$ values of the extracts (Table 2). DPPH radical scavenging abilities in both garlic and onion were not affected by thermal treatment $\left(100^{\circ} \mathrm{C}, 30 \mathrm{~min}\right)$. The results of the present study are supported by the results of a several previous studies. According to Pedraza-Chaverri et

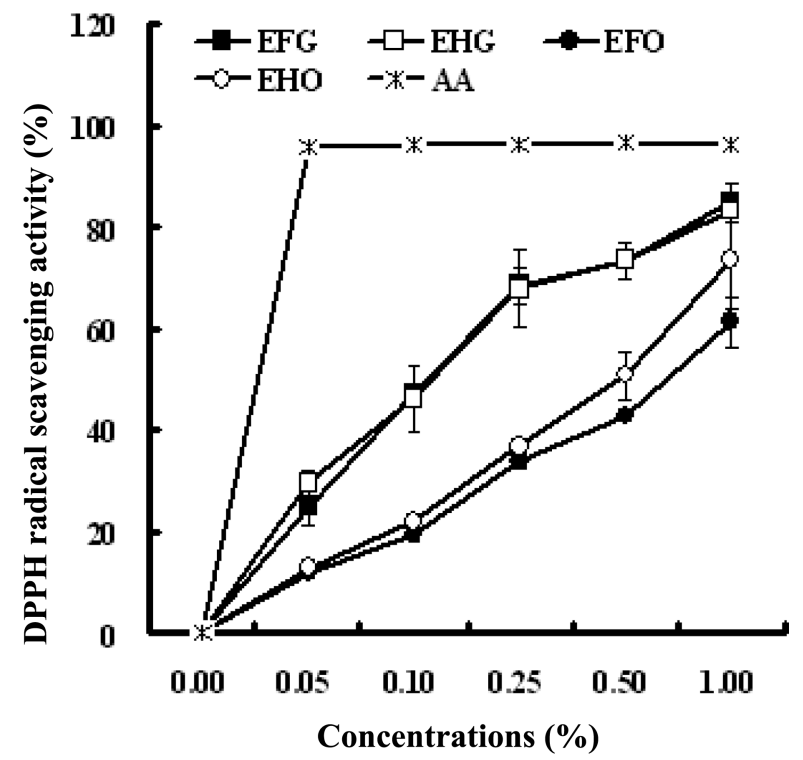

Fig. 1. DPPH radical scavenging activities of ethanolic garlic and onion extracts as affected by pre-heating treatment. EFG, ethanol extracts from fresh garlic; EHG, ethanol extracts from heated garlic; EFO, ethanol extracts from fresh onion; EHO, ethanol extracts from heated onion; AA, ascorbic acid. al. (2006), extracts from garlic with or without heating had similar hydroxyl radical scavenging activities of approximately $40 \%$ at a concentration of $2.61 \mathrm{mg} / \mathrm{mL}$. In addition, aqueous extracts from garlic powder showed similar peroxynitrite scavenging capacity, regardless of boiling (Pedraza-Chaverri et al., 2007). Racchi et al. (2002) reported that boiling $\left(100^{\circ} \mathrm{C}, 30 \mathrm{~min}\right)$ had no effect on the hydroxyl radical scavenging ability of onion. However, according to Gorinstein et al. (2008), although blanching $\left(100^{\circ} \mathrm{C}, 90 \mathrm{sec}\right)$ and frying $\left(100^{\circ} \mathrm{C}, 10 \mathrm{~min}\right)$ white and red onion did not affect the level of antiradical activities against DPPH radicals, boiling $\left(100^{\circ} \mathrm{C}, 10 \mathrm{~min}\right)$ significantly decreased radical scavenging ability. Lipid oxidation in meat and meat products primarily occurs through autoxidation induced by free radicals since it mainly generates hydroperoxides and carbonyl compounds through a three-phase process like initiation, propagation and termination steps (Laguerre et al., 2007). Therefore, strategies to control the free radicals are necessary for protection of meat and meat products from lipid peroxidation. Free radical scavenging abilities of additive agents as an antioxidant are important factor in the oxidative degradation. According to Naveena et al. (2008), chicken patties with the pomegranate rind powder extract that had a relatively high radical scavenging ability and reducing power had lower TBARS values than control or chicken patties with pomegranate juice. In our previous studies (Park and Chin, 2010a, b), methanolic extracts from garlic and onion, both of which had a good antiradical properties, reduced significantly TBARS values of fresh pork patties during refrigerated storage at $4^{\circ} \mathrm{C}(p<0.05)$. Therefore, we suggest that ethanolic extracts used in the present study might be effective in inhibition of lipid peroxidation of meat products.

\section{Ferrous iron chelating ability}

Ferrous iron is recognized as a pro-oxidant because its potent oxidizing activity induces lipid oxidation, which

Table 2. $\mathrm{EC}_{50}$ values of garlic and onion extracts in various antioxidant measurements

\begin{tabular}{|c|c|c|c|c|}
\hline & \multicolumn{4}{|c|}{$\mathrm{EC}_{50}$ values $(\mathrm{g}$ extract $/ 100 \mathrm{~mL})$} \\
\hline & \multicolumn{2}{|c|}{ Garlic } & \multicolumn{2}{|c|}{ Onion } \\
\hline & Unheated & Heated & Unheated & Heated \\
\hline DPPH radical scavenging activity & $0.12^{\mathrm{c}}$ & $0.12^{\mathrm{c}}$ & $0.70^{\mathrm{a}}$ & $0.52^{\mathrm{b}}$ \\
\hline Ferrous iron chelating ability & $0.21^{\mathrm{b}}$ & $0.33^{\mathrm{b}}$ & $4.53^{\mathrm{a}}$ & $4.60^{\mathrm{a}}$ \\
\hline Reducing power & 0.66 & 1.07 & 0.99 & 0.89 \\
\hline
\end{tabular}

${ }^{\mathrm{a}-\mathrm{c}}$ Means with same superscripts within same row are not different $(p>0.05)$.

$\mathrm{EC}_{50}$ value: the effective concentration at which DPPH radicals were scavenged by $50 \%$, ferrous ions were chelated by $50 \%$, and the absorbance was 0.5 for reducing power. $\mathrm{EC}_{50}$ value was obtained by interpolation from linear regression analysis. 
results in the development of an off-flavor (Wong and Kitts, 2001). Ferrous iron-binding properties of garlic and onion extracts were measured using $\mathrm{Fe}^{2+}$-ferrozine complex method. The results revealed that the iron chelating abilities of ethanol extracts from garlic were greater than those of ethanol extracts from onion, regardless of thermal treatments (Fig. 2). Specifically, the ethanol extracts from fresh and heated garlic showed high chelating abilities of $75.6-84.5 \%$ and $62.3-81.1 \%$ at $5.0-10.0 \mathrm{mg} / \mathrm{mL}$, respectively, whereas the onion extracts showed chelating abilities of 3.3-9.6\% and 2.9-8.7\% at the same concentration, respectively. These trends were also found in the concentrations of extract required to chelate $50 \%\left(\mathrm{EC}_{50}\right)$ of the ferrous ions in a chemical mixture (Table 2). Specifically, the $\mathrm{EC}_{50}$ values of the iron chelating abilities of the garlic extracts were lower than those of the onion extracts $(p<0.05)$. As a comparison, EDTA showed a chelating ability of approximately $100 \%$ at $0.05 \mathrm{mg} / \mathrm{mL}$. Free iron acts as an oxidation promoter in muscle system because it produces the hydroxyl radical via the chemical Fenton reaction: $\mathrm{Fe}^{2+}+\mathrm{H}_{2} \mathrm{O}_{2} \rightarrow \mathrm{Fe}^{3+}+\mathrm{OH} \cdot+\mathrm{OH}^{-}$ (Erickson, 2002). In initiation of storage of beef, pork and chicken, levels of non-heme iron are low (Hazell, 1982; Rhee et al., 1996). However, in muscles that are ground, cooked and stored during long period, increase of free iron has been observed (Estevez and Cava, 2004; Kris-

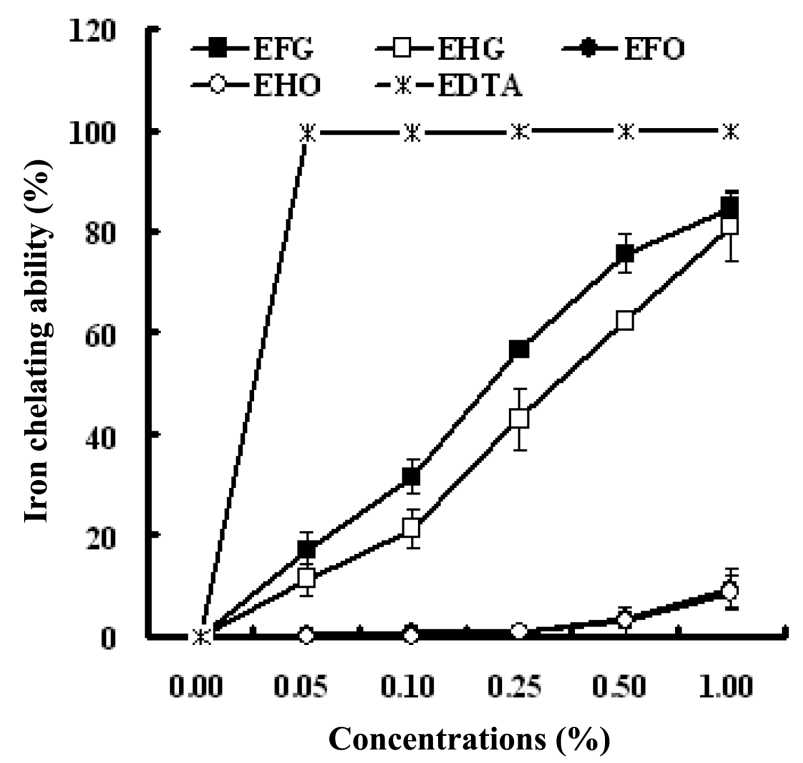

Fig. 2. Ferrous iron chelating abilities of ethanolic garlic and onion extracts as affected by pre-heating treatment. EFG, ethanol extracts from fresh garlic; EHG, ethanol extracts from heated garlic; EFO, ethanol extracts from fresh onion; EHO, ethanol extracts from heated onion; EDTA, ethylenediaminetetraacetic acid disodium salt dihydrate. tensen and Purslow, 2001; Schricker and Miller, 1983). These results suggested that grinding, cooking or storage induced oxidative cleavage of porphyrin ring of heme, and hence caused the release of free ionic iron from heme iron. Therefore, free ionic iron released from heme pigments may be considered as the major catalyst for lipid peroxidation in raw meat stored for long period, and in cooked or ground meats. In our previous studies (Park and Chin, 2010a, b), we found that water extracts from garlic and onion had an excellent iron chelating abilities and significantly inhibited lipid peroxidation of fresh pork patties, as compared to counterparts, although their radical scavenging abilities were very low. Therefore, ethanolic extracts from garlic should be used as free iron chelator in muscle system, regardless of heating (Fig. 2).

\section{Reducing power}

Reducing powers of ethanolic garlic and onion extracts were estimated by measuring the ability of the extracts to reduce ferric iron to ferrous iron. In both garlic and onion, the reducing powers of the extracts increased $(p<0.05)$ with increased concentrations, but were not affected by thermal treatment (Fig. 3). Specifically, reducing powers of the ethanol extracts from fresh and heated garlic ranged from $0.11-0.71$ and $0.11-0.47$ at $0.5-10.0 \mathrm{mg} / \mathrm{mL}$, respectively, whereas the onion extracts ranged from 0.110.52 and $0.12-0.55$ at the same concentration, respec-

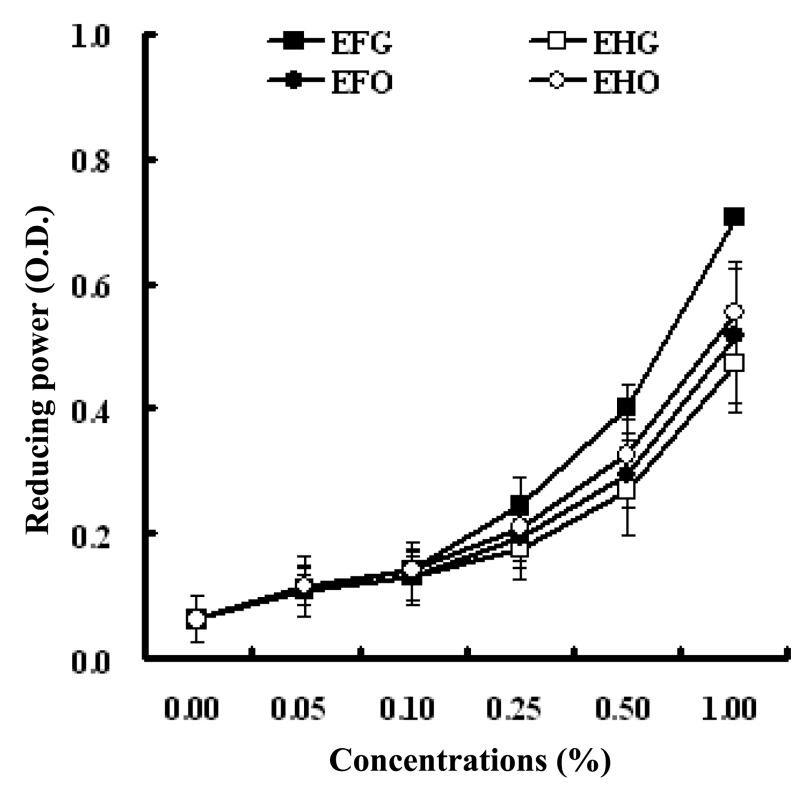

Fig. 3. Reducing powers of ethanolic garlic and onion extracts as affected by pre-heating treatment. EFG, ethanol extracts from fresh garlic; EHG, ethanol extracts from heated garlic; EFO, ethanol extracts from fresh onion; $\mathrm{EHO}$, ethanol extracts from heated onion. 
tively. With regard to the $\mathrm{EC}_{50}$ values, the ethanol extracts from garlic and onion had similar reducing power, regardless of heating (Table 2). However, several studies found that heating garlic and onion bulbs prior to extraction decreased their reducing activity (Gorinstein et al., 2008; Jastrzebski et al., 2007). According to Gorinstein et al. (2008), heat processing (boiling at $100^{\circ} \mathrm{C}$ ) of garlic and onion lead to a decrease in the amounts of their bioactive compounds such as phenolic compounds, resulting in a decrease in the reducing power of extracts. But on the contrary, Dini et al. (2008) found that the ferric reducing antioxidant power of onion increased significantly after boiling at $100^{\circ} \mathrm{C}$ for $20 \mathrm{~min}$. Ferric reducing power assay is developed for direct test of total antioxidant power of compounds, measuring electron-donating ability (Benzie and Strain, 1999). According to Medina et al. (2007), correlations between reducing power of hydroxycinnamic acids and rate of generation of TBARS, and peroxides during oxidation of minced mackerel muscle were -0.96 and -0.97 , respectively. And they concluded that electron-donating ability seems to play an important role for antioxidant efficiency of phenolics. We found that using garlic and onion extracts that had $\mathrm{EC}_{50}$ values ranging from 0.60 to 3.30 could reduce about $50-70 \%$ of TBARS values developed in fresh pork patties stored at $4^{\circ} \mathrm{C}$ for $14 \mathrm{~d}$ (Park and Chin, 2010a,b). In this study, $\mathrm{EC}_{50}$ values of the ethanol extracts from garlic and onion with heating or not ranged from 0.66 to 1.07 . Therefore, we think that they might have potential possibility as antioxidants when they are added to meat products.

\section{Antioxidant activity in linoleic acid emulsion}

The antioxidant activity of ethanolic garlic and onion extracts on peroxidation of linoleic acid was determined. As shown in Fig. 4, the amounts of hydroperoxide in all emulsion systems significantly increased with increased incubation time, and the oxidative activities of linoleic acid were inhibited by the addition of extracts when extracts were added to $0.05 \%$. Specifically, extracts of $0.01 \%$ inhibited the rate of hydroperoxide formation from 2.87 to $16.71 \%$ during incubation time on average. Extracts of $0.05 \%$ had a inhibition rate greater than $24.0 \%$, as compared to control (data not shown). In general, free radicals in a food matrix containing fats or oils act as the initiator of autoxidation, and resulted in the formation of hydroperoxide (Min and Ahn, 2005). A lot of researchers have studied various natural ingredients containing radical scavenging activity because various compounds, including alcohols, aldehydes, hydrocarbons and ketons, produced by decomposition of lipid hydroperoxide contri-

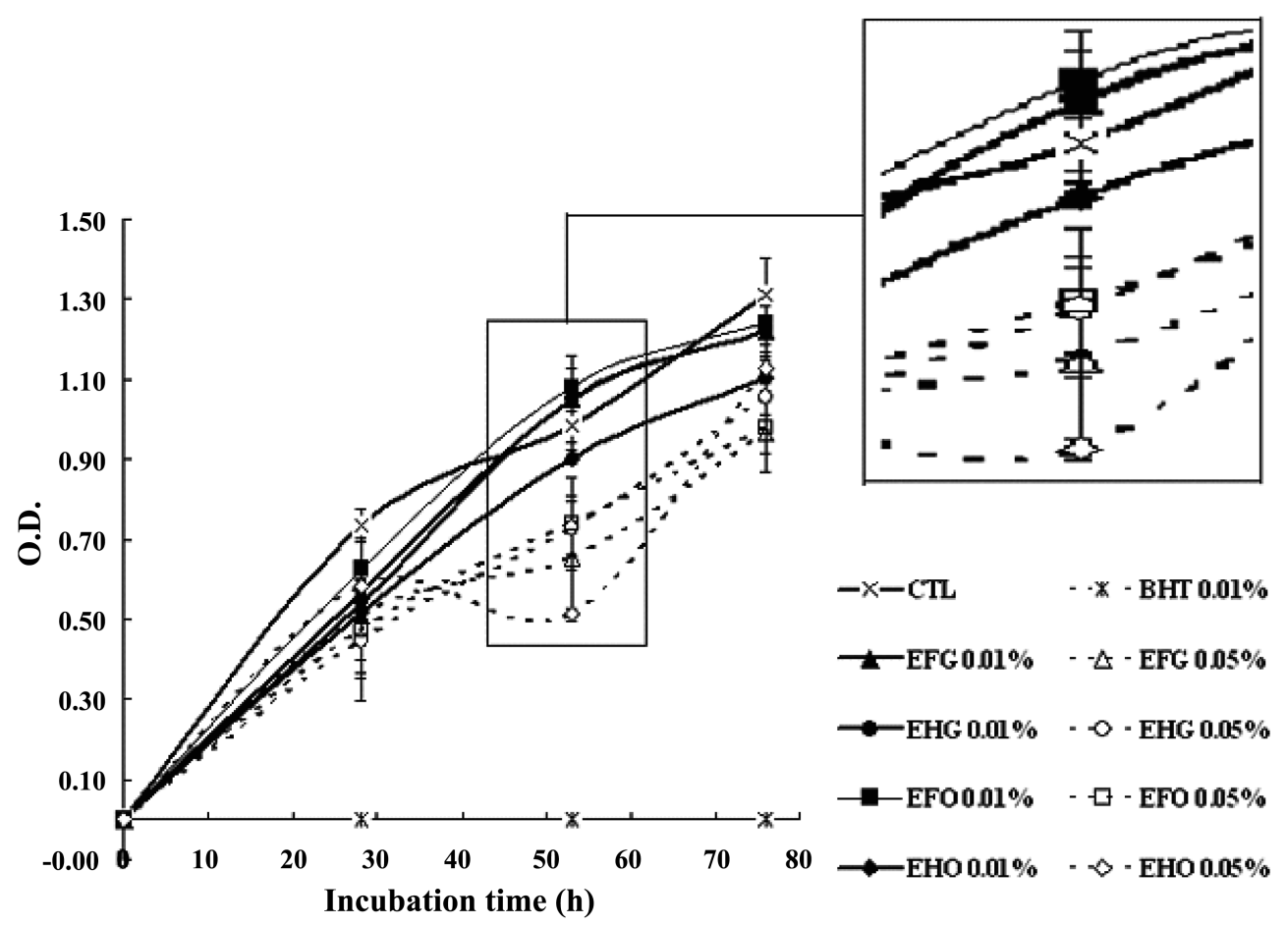

Fig. 4. Antioxidant activities of ethanolic garlic and onion extracts in linoleic acid emulsion systems as affected by preheating. CTL, control without ingredient; BHT, butylated hydroxytoluene; EFG, ethanol extracts from fresh garlic; EHG, ethanol extracts from heated garlic; EFO, ethanol extracts from fresh onion; EHO, ethanol extracts from heated onion. 
bute to flavor deterioration of food (Frankel, 1991). Garlic and onion are known as natural products having radical scavenging activity (Banerjee et al., 2003; Nuutila et al., 2003). In this study, ethanolic garlic and onion extracts showed to have excellent DPPH radical scavenging activities, regardless of heating (Fig. 1). Therefore, their antiradical properties may contribute to the inhibition of hydroperoxide formation in linoleic acid emulsion systems. Similar results were reported by Leelarungrayub et al. (2006) and Nuutila et al. (2003), who found that garlic and onion extracts inhibited the generation of lipid hydroperoxide.

In conclusion, garlic had a higher drying yield than onion, and garlic extracts had greater antioxidant activities than onion extracts. Antioxidant activities of garlic and onion extracts were not significantly affected by the thermal treatment. Both garlic and onion inhibited the formation of hydroperoxide in linoleic acid emulsion systems when ethanol was used as a solvent. Further study will be focused on their application to meat and meat products.

\section{Acknowledgement}

This study was supported by the Brain Korea 21 program (Center for the control of animal hazards using biotechnology, Chonnam National University), Chonnam National University, Gwangju, Korea.

\section{References}

1. Abhayawick, L., Laguerre, J. C., Tauzin, V., and Duquenoy, A. (2002) Physical properties of three onion varieties as affected by the moisture content. J. Food Eng. 55, 253-262.

2. Ahn, J., Grun, I. U., and Mustapha, A. (2007) Effects of plant extracts on microbial growth, color change, and lipid oxidation in cooked beef. Food Microbiol. 24, 7-14.

3. Ali, M., Thomson, M., and Afzal, M. (2000) Garlic and onions: their effect on eicosanoid metabolism and its clinical relevance. Prostaglandins Leukot. Essent. Fatty Acids 62, 55-73.

4. Bae, H. J. and Chun, H. J. (2003) Changes in volatile sulfur compounds of garlic under short-term storage conditions. Korean J. Soc. Food Cookery Sci. 19, 17-23.

5. Banerjee, S. K., Mukherjee, P. K., and Maulik, S. K. (2003) Garlic as an antioxidant: The good, the bad and the ugly. Phytother. Res. 17, 97-106.

6. Bekhit, A. E. D., Geesink, G. H., Ilian, M. A., Morton, J. D., and Bickerstaffe, R. (2003) The effects of natural antioxidants on oxidative processes and met myglobin reducing activity in beef patties. Food Chem. 81,175-187.
7. Benzie, I. F. F. and Strain, J. J. (1999) [2] Ferric reducing/ antioxidant power assay: Direct measure of total antioxidant activity of biological fluids and modified version for simultaneous measurement of total antioxidant power and ascorbic acid concentration. Methods Enzymol. 299, 15-27.

8. Bozkurt, H. (2006) Investigation of the effect of sumac extract and BHT addition on the quality of sucuk (Turkish dry-fermented sausage). J. Sci. Food Agric. 86, 849-856.

9. Branen, A. L. (1975) Toxicology and biochemistry of butylated hydroxyanisole and butylated hydroxytoluene. $\mathrm{J}$. Am. Oil Chem. Soc. 52, 59-63.

10. Corzo-Martinez, M., Corzo, N., and Villamiel, M. (2007) Biological properties of onions and garlic. Trends Food Sci. Technol. 18, 609-625.

11. Crozier, A., Lean, M. E. J., McDonald, M. S., and Black, C. (1997) Quantitative analysis of the flavonoid content of commercial tomatoes, onions, lettuce, and celery. J. Agric. Food Chem. 45, 590-595.

12. Dini, I., Tenore, G. C., and Dini, A. (2008) Chemical composition, nutritional value and antioxidant properties of Allim caepa L. var. tropeana (red onion) seeds. Food Chem. 107, 613-621.

13. Erickson, M. C. (2002) Lipid oxidation of muscle foods. In: Akoh CC, Min DB, editors. Food lipids: Chemistry, nutrition, and biotechnology. 2nd ed., Marcel Dekker, NY, pp. 365-411.

14. Estevez, M. and Cava, R. (2004) Lipid and protein oxidation, release of iron from heme molecule and colour deterioration during refrigerated storage of liver pâté. Meat Sci. 68, 551558.

15. Frankel, E. N. (1991) Recent advances in lipid oxidation. $J$. Sci. Food Agric. 54, 495-511.

16. Gorinstein, S., Drzewiecki, J., Leontowicz, H., Leontowicz, M., Najman, K., Jastrzebski, Z., Zachwieja, Z., Barton, H., Shtabsky, B., Katrich, E., and Trakhtenberg, S. (2005) Comparsion of the bioactive compounds and antioxidant potentials of fresh and cooked Polish, Ukrainian, and Israeli garlic. J. Agric. Food Chem. 53, 2726-2732.

17. Gorinstein, S., Leontowicz, H., Leontowicz, M., Drzewiecki, J., Najman, K., Katrich, E., Barasch, D., Yamamoto, K., and Trakhtenberg, S. (2006) Raw and boiled garlic enhances plasma antioxidant activity and improves plasma lipid metabolism in cholesterol-fed rats. Life Sci. 78, 655-663.

18. Gorinstein, S., Leontowicz, H., Leontowicz, M., Namiesnik, J., Najman, K., Drzewiecki, J., Cvikrova, M., Martincova, O, Katrich, E., Trakhtenberg, S. (2008) Comparsion of the main bioactive compounds and antioxidant activities in garlic and white and red onions after treatment protocols. J. Agric. Food Chem. 56, 4418-4426.

19. Hazell, T. (1982) Iron and zinc compounds in the muscle meats of beef, lamb, pork and chicken. J. Sci. Food Agric. 33, 1049-1056.

20. Huang, S. J., Tsai, S. Y, and Mau, J. L. (2006) Antioxidant properties of methanolic extracts from Agrocybe cylindracea. LWT-Food Sci. Technol. 39, 378-386.

21. Jastrzebski, Z., Leontowicz, H., Leontowicz, M., Namiesnik, 
J., Zachwieja, Z., Barton, H., Pawelzik, E., Arancibia-Avila, P., Toledo, F., and Gorinstein, S. (2007) The bioactivity of processed garlic (Allium sativum L.) as shown in vitro and in vivo studies on rats. Food Chem. Toxicol. 45, 1626-1633.

22. Kristensen, L. and Purslow, P. P. (2001) The effect of processing temperature and addition of mono- and di-valent salts on the heme- nonheme-iron ration in meat. Food Chem. 73, 433-439.

23. Kristinova, V., Mozuraityte, R., Storro, I., and Rustad, T. (2009) Antioxidant activity of phenolic acids in lipid oxidation catalyzed by different prooxidants. J. Agric. Food Chem. 57, 10377-10385.

24. Laguerre, M., Lecomte, J., and Villeneuve, P. (2007) Evaluation of the ability of antioxidants to counteract lipid oxidation: Existing methods, new trends and challenges. Prog Lipid Res. 46, 244-282.

25. Lanzotti, V. (2006) The analysis of onion and garlic. J. Chromatogr. A. 1112, 3-22.

26. Le, K., Chiu, F., and Ng, K. (2007) Identification and quantification of antioxidants in Fructus lycii. Food Chem. 105, 353-363.

27. Leelarungrayub, N., Rattanapanone, V., Chanarat, N., and Gebicki, J. M. (2006) Quantitative evaluation of the antioxidant properties of garlic and shallot preparations. Nutr. 22, 266-274.

28. Lin, J. Y. and Tang, C. Y. (2007) Determination of total phenolic and flavonoid contents in selected fruits and vegetables, as well as their stimulatory effects on mouse splenocyte proliferation. Food Chem. 101, 140-147.

29. Makris, D. P. and Rossiter, J. T. (2001) Domestic processing of onion bulbs (Allium cepa) and asparagus spears (Asparagus officinalis): Effect on flavonol content and antioxidant status. J. Agric. Food Chem. 49, 3216-3222.

30. Medina, I., Gallardo, J. M., Gonzalez, M. J., Lois, S., and Hedges, H. (2007) Effect of molecular structure of phenolic families as hydroxycinnamic acids and catechins on their antioxidant effectiveness in minced fish muscle. J. Agric. Food Chem. 55, 3889-3895.

31. Miean, K. H. and Mohamed, S. (2001) Flavonoid (myricetin, quercetin, kaempferol, luteolin, and apigenin) content of edible tropical plants. J. Agric. Food Chem. 49, 3106-3112.

32. Min, B. and Ahn, D. U. (2005) Mechanism of lipid peroxidation in meat and meat products-A review. Food Sci. Biotechnol. 14, 152-163.

33. Naveena, B. M., Sen, A. R., Vaithiyanathan, S., Babji, Y., and Kondaiah, N. (2008) Comparative efficacy of pomegranate juice, pomegranate rind powder extract and BHT as antioxidants in cooked chicken patties. Meat Sci. 80, 1304-1308.

34. Nuutila, A. M., Puupponen-Pimia, R., Aarni, M., OksmanCaldentey, K. M. (2003) Comparison of antioxidant activities of onion and garlic extracts by inhibition of lipid peroxidation and radical scavenging activity. Food Chem. 81, 485493.
35. Park, S. Y. and Chin, K. B. (2010a) Effects of onion on physicochemical properties, lipid oxidation and microbial growth of fresh pork patties. Int. J. Food Sci. Technol. 45, 11531160.

36. Park, S. Y. and Chin, K. B. (2010b) Evaluation of pre-heating and extraction solvents in antioxidant and antimicrobial activities of garlic, and their application in fresh pork patties. Int. J. Food Sci. Technol. 45, 365-373.

37. Pedraza-Chaverri, J., Medina-Campos, O. N., Avila-Lombardo, R., Zuniga-Bustos, A. B., and Orozco-Ibarra, M. (2006) Reactive oxygen species scavenging capacity of different cooked garlic preparations. Life Sci. 78, 761-770.

38. Pedraza-Chaverri, J., Medina-Campos, O. N., and SegovianoMurillo, S. (2007) Effect of heating on peroxynitrite scavenging capacity of garlic. Food Chem. Toxicol. 45, 622-627.

39. Racchi, M., Daglia, M., Lanni, C., Papetti, A., Govoni, S., and Gazzani, G. (2002) Antiradical activity of water soluble components in common diet vegetables. J. Agric. Food Chem. 50, 1272-1277.

40. Randhir, R., Kwon, Y. I., and Shetty, K. (2008) Effect of thermal processing on phenolics, antioxidant activity and healthrelevant functionality of select grain sprouts and seedlings. Inn. Food Sci. Emerg. Technol. 9, 355-364.

41. Rhee, K. S., Anderson, L. M., and Sams, A. R. (1996) Lipid oxidation potential of beef, chicken, and pork. J. Food Sci. 61, 8-12.

42. Roy, M. K., Takenaka, M., and Isobe, S. (2007) Thermal processing enhances anti-radical activity and reduces pro-oxidant activity in water-soluble fraction of selected Allium vegetables. J. Sci. Food Agric. 87, 2259-2265.

43. Schricker, B. R. and Miller, D. D. (1983) Effects of cooking and chemical treatment on heme and nonheme iron in meat. J. Food Sci. 48, 1340-1344.

44. Shin, D. B., Seog, H. M., Kim, J. H., and Lee, Y. C. (1999) Flavor composition of garlic from different area. Korea $J$. Food Sci. Technol. 31, 293-300.

45. Tang, X. and Cronin, D. A. (2007) The effects of brined onion extracts on lipid oxidation and sensory quality in refrigerated cooked turkey breast rolls during storage. Food Chem. 100, 712-718.

46. Wong, P. Y. Y. and Kitts, D. D. (2001) An iron binding assay to measure activity of known food sequestering agents: studies with buttermilk solids. Food Chem. 72, 245-254.

47. Yen, G. C. and Hsieh, C. L. (1998) Antioxidant activity of extracts from Du-zhong (Eucommia ulmoides) toward various lipid peroxidation models in vitro. J. Agric. Food Chem. 46, 3952-3957.

48. Yin, M. C. and Cheng, W. S. (2003) Antioxidant and antimicrobial effects of four garlic-derived organosulfur compounds in ground beef. Meat Sci. 63, 23-28.

(Received 2010.1.19/Revised 1st 2010.7.5, 2nd 2010.7.21/ Accepted 2010.7.22) 